compression. Might I suggest to these gentlemen that they give electrical stimulation a trial-it does not cause bleeding and the neat "electronic" foam polyethylene gaiters" (Donns Surgical Ltd) are much easier to apply and remove than a stocking. Moreover, electrical stimulation has given me ten years in general surgery without a serious pulmonary embolus, even when the patient has cancer.

To Mr Clayton may I say that the gaiter may not have a good name in Leeds, where it was tried in the orthopaedic department for hip replacements. It was not satisfactorybut no other method is either with this operation.

F S A DORAN

Ledbury,

Herefordshire

Doran, F S A, Drury, $M$, and Sivyer, A, British Fournal of Surgery, 1964, 51, 486

2 Hodgson, D C, Anaesthesia, 1964, 19, 96.

Doran, F S A, and White, M, British fournal of Surgery, 1967, 54, 686

Browse, N L, and Negus, D, British Medical fournal, 1970, 3, 615.

5 Sharnhoff, J G, Lancet, 1969, 2, 292.
${ }^{6}$ Powley, J M, and Doran, F S A, Lancet, 1973, 1, 406.

\section{Coronary artery disease and} coalworkers' pneumoconiosis

SIR,-As the surviving coauthors of one of the papers $^{1}$ quoted by Dr Dewi Davies (16 October, p 925) we would like the opportunity to reply to his implied criticisms.

He says, "They too failed to see what needs to be enunciated as a principle: that any disease which produces a high mortality is inevitably associated with a lower mortality from other and independent conditions." Table I of our paper shows that of 920 deaths of those with all grades of simple and complicated pneumoconiosis, 658 occurred above the age of 64 . It can hardly be said that these men were dying before they were at risk from coronary thrombosis. Nonkin et al, ${ }^{2}$ after pointing out that their series of cases was checked both clinically and at necropsy for evidence of obstructive emphysema, state that the great majority of their deaths from obstructive emphysema occurred in the seventh decade and that in a similar population the greatest number of deaths from acute myocardial infarction also occurred in the same decade, so that Dr Davies is wrong in his assumption that those with pneumoconiosis or chronic obstructive emphysema die before the age at which coronary thrombosis might be expected.

Dr Davies states that there is no evidence that the presence of chronic lung disease would produce better anastomoses in cardiac muscle and that the greatest stimulus to these anastomoses is coronary atheroma. However, Nonkin et $a l^{2}$ showed the distribution of coronary atheroma among their 104 patients with emphysema to be similar to that in other groups of like ages. Mitchell et $a l^{3}$ studied a group of 232 necropsy cases with moderate or severe coronary atherosclerosis; of these, 77 had chronic airways obstruction and 155 had not. Acute myocardial infarction was shown in $32 \%$ of those without airways obstruction and in only $17 \%$ of those with airways obstruction. If the incidence of atheroma is roughly the same in both groups is it not reasonable to suggest some other factor such as chronic hypoxaemia to explain the lower mortality rate from coronary thrombosis in those with advanced pneumoconiosis or severe chronic obstructive airways disease?

Dr Davies does not produce facts and figures to refute our findings, nor those of Nonkin et al and Mitchell et al. Nor does he show that on the balance of probabilities coronary thrombosis is likely to prove more fatal in those with pneumoconiosis than in those without.

G B Rooke

A N DEMPSEY

F G WARD

Manchester

Lindars, D G, et al, fournal of Pathology, 1972, 108,

249. of Internal Medicine, 1964, 113, 42.

Review of Respiratory Diseases, 1968, 98, 611 .
Rerican

\section{Dealing with alcoholism}

SIR,-In your leading article under this title (16 October, p 902) you describe a recent symposium at the Institute of Psychiatry, London University, as arousing a good deal of controversy. The basic rift was evidently between those who supported the policy of the World Health Organisation and those who, like Dr Christopher Clayson, are not in agreement. The crux of the matter is that the British and US governments and others have not appreciated that the policy of their drink trades has been directed to steadily increasing the sale and therefore the consumption of alcohol, whereas that of the WHO is to diminish consumption as far as possible. Any government can obtain quickly and easily a huge sum from taxing the sale of drink, but the damage done to the economy and to the health of the nation costs far more than the money gained by taxation. The cost to France in treating alcoholics was found by de Gaulle to be four times greater than the taxes gathered from the liquor trade.

At the Maudsley symposium Dr Wolfgang Schmidt represented the WHO views because he is an expert on the scientific statistical discoveries of the late Sully Ledermann of Paris. This work has been so important that it is being further developed under WHO auspices at Helsinki and Toronto. Dr Schmidt's contribution was therefore of the highest importance.

Your leading article in 1974 supporting WHO policy ${ }^{1}$ apparently inspired our experts on alcoholism to rethink their medical positions, with the happy result that the Erroll proposals and Clarke's private member's Bill failed to reach the statute book through the brilliant leadership and eloquence of Sir Bernard Braine, MP. At the Maudsley it is evident that, just as in the cigarette controversy of 15 years ago Sir Aubrey Lewis had to defend the work of Sir Austin Bradford Hill against an attack on it by a professorial colleague, so today, when wrong decisions are made, the same institute can produce book such as that by Zacune and Hensman' approved by the WHO, but at the same time their opponents can state, as you report, that the publication Alcoholism and Treatment ${ }^{3}$ represents "a heartening trend" although its policy is to stop inducing alcoholics to be abstinent and to teach them to be "moderate drinkers." This proposal has met with the strongest possible opposition in America. Dr Max Glatt in London has tried out the policy of treating alcoholics withou insisting on abstinence but gave it up as almost useless when compared with programmes such as those of Alcoholics Anonymous. Few patients fail to appreciate the powerful impact of the group sentiment of AA, which includes those of every view including agnosticism, though many of these contribute more than their share to AA. The organisation has been brilliant over a period of 40 years and it is recommended by many governments as an efficient therapeutic agency.

An American journal ${ }^{4}$ describes the Rand Corporation's project to which you refer $^{3}$ somewhat in the following terms. Dr Morris Chafetz, when director of the National Institute of Alcohol Abuse and Alcoholism awarded $\$ 489000$ to the Rand Corporation to carry out a project in which alcoholics are told that their illness is simply due to uncontrolled drinking, but if they drink moderately this will be better than if they aim at abstinence. No explanation was given of how these addicts could become moderate drinkers. It was claimed that of 1340 patients, $70 \%$ had shown "significant improvement" but this was never defined. Of the total number, $23^{\circ}$ had been abstinent for at least six months while another $23 \%$ had been "drinking normally," a third $23 \%$ had been drinking heavily at times but otherwise were abstinent, and $30^{\circ}$ were unchanged or worse. Again there was no definition of normal drinking. It is noticeable that one function of drink advertisements is to describe as normal drinking what is in fact excessive.

May I suggest that once again you have performed a valuable service in stating what the views are of those who support and those who oppose the policy of the WHO. You mention the qualities necessary in a man who will lead the new pattern of services needed in Britain to stem the rising tide of alcoholism. May I suggest that the first consideration is that he supports the policy of the WHO?

\section{A SPENCER PAterson}

London $\mathrm{W}^{\prime} 1$

British Medical fournal, 1974, 2, 132

Drugs. Alcohol and Tobacco in Britain, comp J Zacune and C Hensman. London, Heinemann Medical, 1971

Armor, D J, Polich, J M, and Stambul, H B, Alco holism and Treatment. Santa Monica, Rand CorporaTwin Circle, the National Catholic Press, 11 July 1976.

SIR,-Fifty years of experience in the treatment of alcoholism suggest that your leading article (16 October, p 902) "Dealing with alcoholism" might be more appropriately titled "Mishandling alcoholism." A simple problem is complicated by lack of understanding. The existing confusion is due to the absence of universal concrete policies and positive thought.

The retrogressive step of treating alcoholism while administering alcohol is too alarming to ignore and the recent "research" is so ridiculous that this urgent protest must be made. Any attempt to extinguish a fire by pouring petrol over it would be disastrous. If a drug addict were to be withdrawn from his addiction it would be criminal to reintroduce the drug. Alcohol is just such a drug.

There is only one treatment for alcoholism which is logical and that is to remove the cause and not to replace it. Ingestion of alcohol causes alcoholism. If the patient suffering from alcoholism fails or refuses to become abstinent his disability will persist. Therapists who encourage alcohol ingestion in such patients cannot really understand the problem. No attempt should be made to improve the 